\title{
GEONDICADORES EM AMBIENTES COSTEIROS: A LAGOA DO PEIXE (RS) E AS ANOAMALIAS DE PRECIPITAÇÃO RELACIONADAS AO MODO ANULAR DO HEMISFÉRIO SUL E O EL NIÑO-OSCILAÇÃO SUL
}

\author{
Venisse Schossler ${ }^{(\mathrm{a})}$, Jefferson Cardia Simões ${ }^{(\mathrm{b})}$, Francisco Eliseu Aquino ${ }^{(\mathrm{c})}$ \\ (a) Centro Polar e Climático, Instituto de Geociências, UFRGS, venisse.schossler@ufrgs.br \\ (b) Centro Polar e Climático, Instituto de Geociências, UFRGS, jefferson.simoes@ufrgs.br \\ (c) Centro Polar e Climático, Instituto de Geociências, UFRGS, francisco.aquino@ufrgs.br
}

Eixo: 3 - Climatologia em diferentes níveis escalares: mudanças e variabilidades

\begin{abstract}
Resumo
Este estudo investiga variações em um geoindicador costeiro, a Lagoa do Peixe (LP), associadas a eventos anômalos de precipitação pluviométrica (PP) relacionados ao Modo Anular do Hemisfério Sul (SAM) e ao El Niño - Oscilação Sul (ENOS). As anomalias de PP foram estatisticamente correlacionadas aos modos de variabilidade climática por matrizes de classificação e teste $t$. Comparou-se imagens Landsat em períodos de precipitação acima e abaixo da média na Planície Costeira do Rio Grande do Sul. Foi encontrada correlação significativa positiva entre as anomalias de precipitação na PCRGS com o ENOS, e negativa com o SAM, com tendência a redução na precipitação média, associada ao aumento de períodos de SAM+ e intensificação dos eventos El Niño e La Niña. As variações observadas na LP indicam que a redução na precipitação média pode acelerar o processo de colmatação da LP pelo transporte de areias secas do campo de dunas adjacente.
\end{abstract}

Palavras chave: variabilidade climática; ambiente costeiro; mudanças climáticas.

\section{Considerações iniciais}

A Planície Costeira do Rio Grande do Sul (PCRGS) é uma extensa faixa litorânea de 615 km (Figura 1), de características morfodinâmicas intermediárias a dissipativas (CALLIARI et al., 2006). Como toda região costeira, é caracterizada como um ambiente susceptível a intervenção humana e mudanças climáticas (BAILY E NOWELL, 1996). Morton et al. (2000) apontam que o aumento/redução da precipitação resultantes da variabilidade climática, e.g. El Niño-Oscilação Sul (ENOS) e o Modo Anular do Hemisfério Sul (SAM), são também fatores atuais de mudanças ambientais em regiões costeiras.

Diversos trabalhos associam as anomalias de precipitação aos modos de variabilidade climática (e.g. GRIMM, 2000, GILLET et al., 2006; GARREAUD et al., 2009). O El Niño (EN) refere-se ao aumento da Temperatura da Superfície do Mar (TSM) no oceano Pacífico Tropical, enquanto a La Niña (LN) é a fase oposta. Bjerknes (1969) foi o primeiro autor a propor uma conexão entre o El Niño e a Oscilação Sul (OS). Atualmente os trabalhos referem-se ao acoplamento oceano/atmosfera ENOS. O SAM é uma variação na massa atmosférica, entre médias e altas latitudes no Hemisfério Sul (HS), que atua de maneira 
constante no clima dessas regiões (GONG E WANG, 1999). O SAM é definido como a diferença normalizada da Pressão ao Nível do Mar (PNM) mensal entre $40^{\circ} \mathrm{S}$ e $70^{\circ} \mathrm{S}$
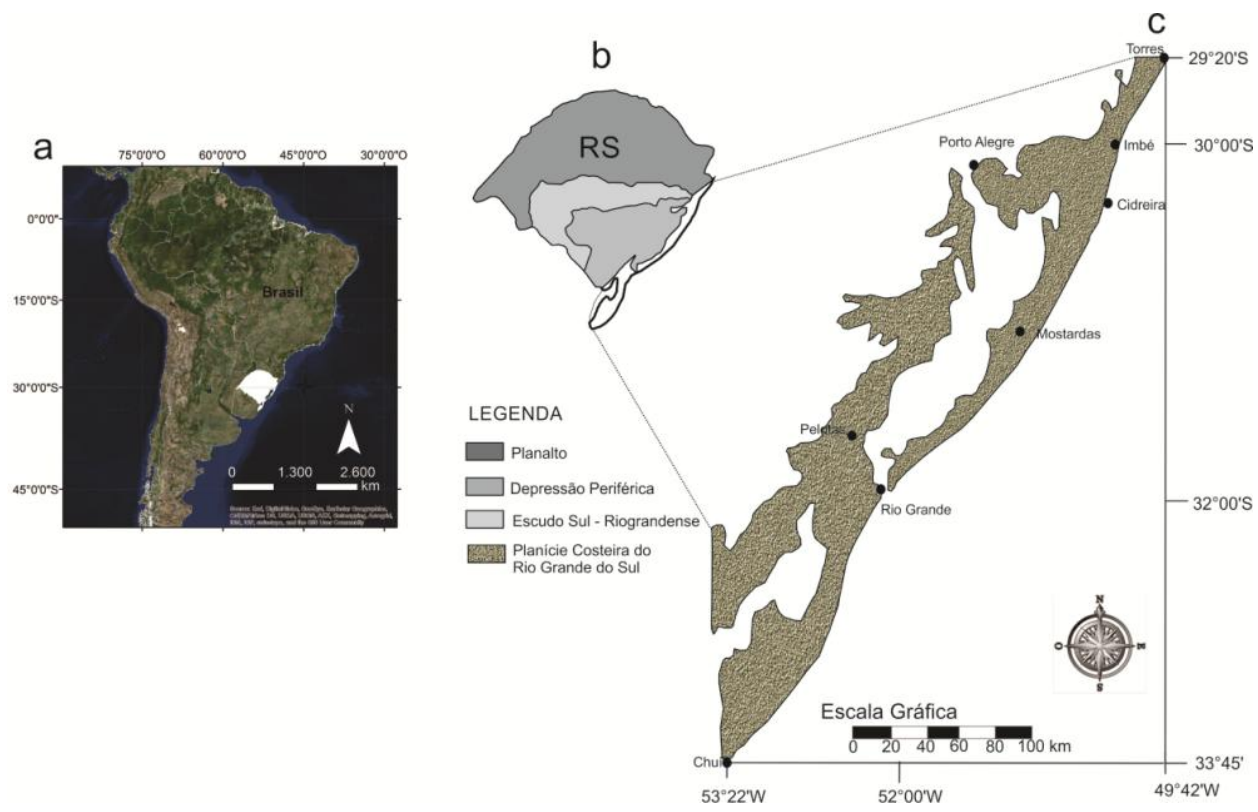

Figura 1 - Localização do Rio Grande do Sul na América do Sul (a); divisão geomorfológica do estado do Rio Grande do Sul (b) de acordo com Carraro et al (1974) e; localização da Planície Costeira do Rio Grande do Sul (c).

Silvestri e Vera (2003) examinaram os efeitos do SAM sobre a precipitação no sudeste da América do Sul (AS), e constataram que, particularmente durante a primavera, a atividade do SAM produz forte modulação do sinal do ENOS e da precipitação nessa região. Grimm et al. $(1998,2000)$ também encontraram relação entre o aumento da temperatura do ar e precipitação com ENOS, ao analisarem especificamente a Região Sul do Brasil. Reboita et al. (2009) associam o SAM, em fase negativa, ao aumento de ciclogênese no sul da $\mathrm{AS}$, ao mesmo tempo em que a fase oposta predispõe a mesma região à situação inversa.

A área de estudo deste trabalho é a Lagoa do Peixe (LP), localizada no Parque Nacional da Lagoa do Peixe (PNLP) no litoral médio da PCRGS (VILLWOCK E TOMAZELLI, 1995). O PNLP possui 344 km² de área (Figura 2) e a LP, rasa laguna com $30 \mathrm{~cm}$ de profundidade média, $35 \mathrm{~km}$ de comprimento e $2 \mathrm{~km}$ de largura, posicionada paralelamente a linha de costa.

A LP não possui tributários, porém apresenta um canal intermitente com o Oceano Atlântico. Sua forma retilínea e orientação NE-SW a condiciona a processos costeiros ocasionados pelos ventos, marés, ondas e correntes atuantes. Segundo classificação geomorfológica de Kjerfve e Maggil (1989), a LP é uma laguna do tipo choked. Lagunas choked são aquelas localizadas em costas com alta energia de ondas, dominadas 
pelo vento, apresentando intensa deriva litorânea, podendo apresentar um ou mais canais. Variações da salinidade são mais frequentes nas lagunas do tipo choked onde o nível d'água pode se elevar vários metros sazonalmente, em resposta a tempestades e oscilações no regime de precipitação.
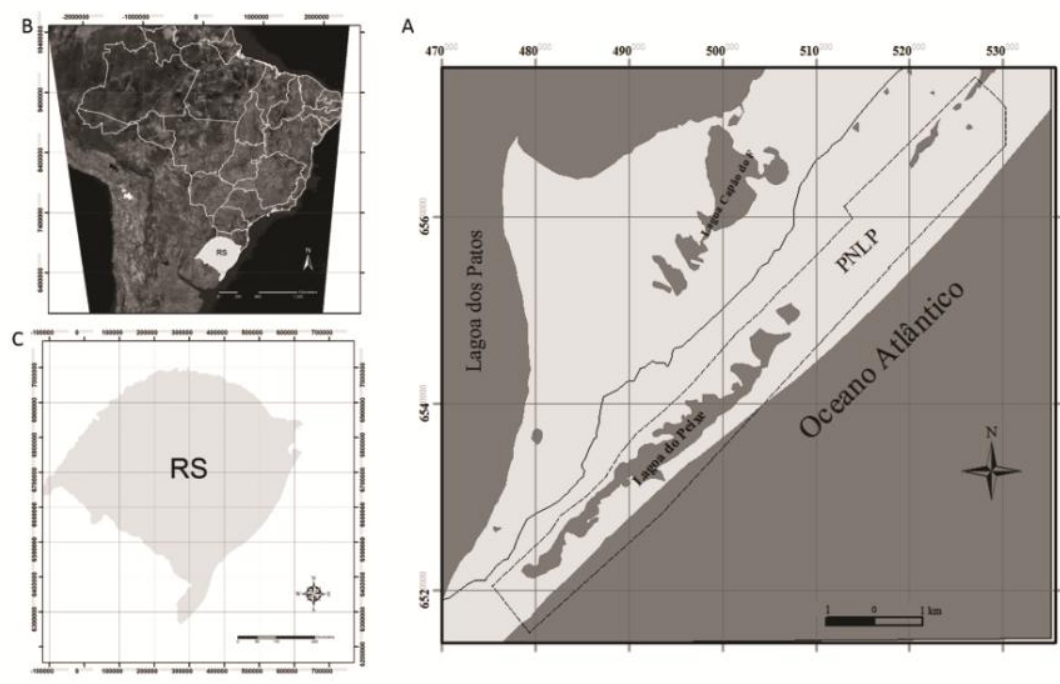

Figura 2 - Mapa de localização do Parque Nacional da Lagoa do Peixe. O polígono tracejado indica os limites do parque no litoral médio do Rio Grande do Sul.

Devido a sua baixa profundidade, a LP é bastante vulnerável às variações nos padrões de precipitação na região, sejam elas de pequenas ou de grandes proporções, pois podem fazer variar sua salinidade, e, consequentemente, vir a prejudicar seu rico ecossistema. Sendo assim, pode ser considerado um excelente geoindicador de variações de precipitação e mudanças no clima. Assim, o presente estudo analisa a relação existente entre as anomalias sazonais de precipitação no PNLP e as fases positivas e negativas do SAM e do ENOS, dois importantes modos de variabilidade climática no HS, relacionados às variações de precipitação no sul do Brasil (eg. GRIMM et al. 1998, 2000; REBOITA et al. 2009).

\section{Metodologia}

O grande espaçamento entre os pluviômetros no Brasil dificulta o acesso a dados de precipitação bem distribuídos. Com a finalidade de monitorar orbitalmente a precipitação em uma grade regular de dados dos trópicos e subtrópicos o Tropical Rainfall Measuring Mission (TRMM), é uma alternativa confiável para a área de estudo. O TRMM foi lançado em dezembro de 1997 em uma parceria entre a Agência Espacial Norte-Americana (NASA) e a Agência de Exploração Aeroespacial do Japão (JAXA). O presente estudo foi concentrado em dados de precipitação do período que compreende 1998-2013 do TRMM, em uma malha de 77 pontos sobre a PCRGS. 
Os resultados das anomalias de precipitação pluviométrica (PP) foram comparados aos índices MEI e SAM do mesmo período mensalmente, sendo aqui indicadas como PP- (precipitação abaixo da média) e PP+ (precipitação acima da média).

O SAM é definido como a diferença normalizada da PNM mensal entre $40^{\circ} \mathrm{S}$ e $70^{\circ} \mathrm{S}$ (GONG e WANG 1999). O índice utilizado foi o de Nan e Li (2003), obtido na National Key Laboratory of Numerical Modeling for Atmospheric Sciences and Geophysical Fluid Dynamics LASG, Institute of Atmospheric Physics, Beijing, China (http://ljp.lasg.ac.cn/dct/page/65572), 1998-2013. O índice do ENOS utilizado foi o Multivariate ENSO Index (MEI), que é formado a partir das medidas de seis importantes variáveis sobre o Pacífico Tropical: PNM, componentes do vento na superfície meridional e zonal, temperatura da superfície do mar, temperatura da superfície do ar e percentual de cobertura de nuvens, disponíveis no sitio da NOAA (National Oceanic and Atmospheric Administration, United States, Departamento of Commerce, EUA, http://www.esrl.noaa.gov/psd/enso/mei/index.html). Os eventos de precipitação foram identificados de forma qualitativa e visual.

Para comparar os três índices foi primeiramente aplicada a Estatística Descritiva. O estudo comparativo entre os índices de anomalias da PP, MEI e SAM, na série 1998-2013, permitiu a realização de análises mensais. Logo, com a finalidade de avaliar a relação entre esses três índices foram geradas matrizes de classificação em função discriminante (3x3) a qual se aplicou os scores Hit Rate (Percentual Corretamente Classificado pela função discriminante - Equação 1) e o teste $t$ de student (Equação 2) para a precisão da classificação em análise discriminante de cada matriz. As matrizes foram organizadas em três classes $(-1,0,1)$, classificando cada tercil em: abaixo da média de PP (-1), na média (0) e acima da média (1). Quando o resultado de $t$ é superior a 1,96 existe correlação entre os índices, pois sua significância será inferior a 0,05 (HAIR et al. 2009).

$$
\begin{aligned}
& p=\frac{n}{N} \times 100 \\
& t=\frac{p-0,33}{\sqrt{\frac{0,8 s(1-0,8 s)}{N}}}
\end{aligned}
$$

Onde:

$p=$ percentual corretamente classificado

$t=$ teste $t$ de student

$\mathrm{N}=$ tamanho da amostra

$n=$ número corretamente classificado

Berger (1997) elaborou uma lista para verificar a adequação de geoindicadores, aqui aplicada a lagunas. De acordo com o autor, o nível de lagos, lagoas e lagunas podem indicar mudanças no clima. Com a 
finalidade de interpretar e analisar a variação hídrica do geoindicador foram identificados 7 eventos de PP, de 5 meses ou mais, simultâneos a fases positivas/negativas dos índices SAM e MEI. Uma vez caracterizados os eventos, foram selecionadas imagens Landsat (sensores TM e ETM+) do mesmo período onde os geoindicadores estivessem visíveis, disponibilizadas gratuitamente no sitio do Instituto Nacional de Pesquisas Espaciais, o INPE (http://www.dgi.inpe.br/CDSR/).

\section{Resultados}

As anomalias de precipitação na PCRGS apresentam correlação negativa entre a PP e o SAM $(t=2,77 ; \alpha$ $<05)$ e positiva com MEI $(t=2,11 ; \alpha<0,05)$. No período 1998-2013, foram encontrados 7 eventos de PP+ e PP-. As médias de precipitação mensais revelam eventos de PP correspondentes, principalmente, ao SAM+ e o MEI-, como é possível ver na figura 3a. São sete eventos de meses consecutivos de anomalias de PP, dos quais cinco são de estiagem e dois são de precipitação acima da média. Dos cinco eventos de PP- (Figuras 3b-1, 3b-2, 3b-4, 3b-6 e 3b-7) quatro ocorrem em fase do SAM+ (Figuras 3b-1, 3b-2, 3b-4 e 3b-6) e um em fase MEI- (Figuras 3b-7). Os eventos 1, 2 e 4 (Figuras 3b-1, 3b-2 e 3b-4), ocorridos em 1998-1999, 1999-2000 e 2007-2008, respectivamente, são marcados pela evolução dos valores positivos do índice SAM e negativos do MEI, enquanto a precipitação se manteve abaixo da média da PCRGS (126 $\mathrm{mm}$ ) por cinco ou seis meses consecutivos. Nas figuras 3b-1, 3b-2 e 3b-4 é possível notar que os valores do SAM são menos homogêneos que os do MEI, que sempre apresenta valores estáveis entre -0,8 e -1,25. Os eventos 1 e 2 ocorreram no período compreendido entre julho de 1998 e março de 2001, marcado por um dos mais longos eventos LN já registrados, e o evento 4 entre 2007 e 2008, confirmado como um evento LN de moderada intensidade. Além disso, cabe destacar que todos os três eventos ocorreram entre a primavera e o verão.

A figura 3b-7 mostra o último evento de PP- encontrado na série de anomalias para toda PCRGS, no qual a PP ficou abaixo da média por 5 meses, também entre a primavera e o verão (2011-2012). Nesse período o índice SAM oscilou entre valores positivos e negativos, porém o MEI se manteve negativo todo o tempo, de acordo com o evento LN de fraca intensidade entre 2011 e 2012. Os eventos 3 e 5 (Figuras 3b-3 e 3b-5) apresentam anomalias positivas de PP por longos períodos: um ano inteiro no evento 3 (2002) e sete meses no evento 5 (2009-2010). No ano de 2002, apesar de não apresentar os índices de variabilidade sempre com o mesmo sinal, a maior parte dos meses possuem SAM- (8 meses) e MEI+ (9 meses). No evento 5, todos os 7 meses de duração foram de MEI+ dos quais 5 foram de SAM-, entre a primavera e o verão, como os eventos 1, 2, 4 e 7. O ano de 2002 marca um evento EN de intensidade moderada, bem como o biênio 2009-2010, porém a evolução do evento EN 2009-2010 foi um forte evento 


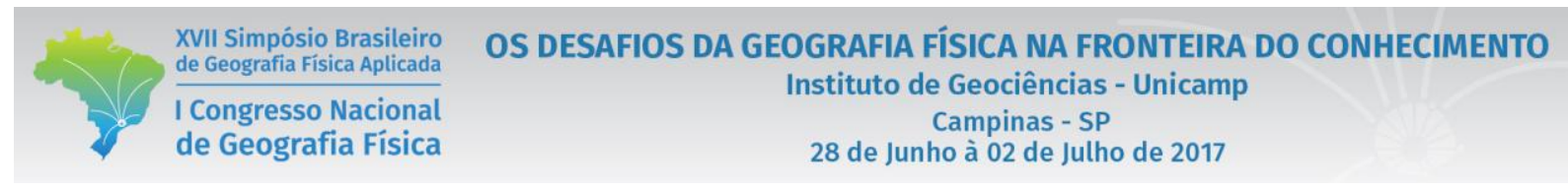

LN entre julho de 2010 e abril de 2011. Neste período a PCRGS, estava sofrendo com estiagem por praticamente 10 meses (Figura 3b-6) com o MEI invertendo o sinal, de positivo para negativo, na metade do ano de 2010 e o SAM se mantendo em fase positiva por todo período do evento 6.

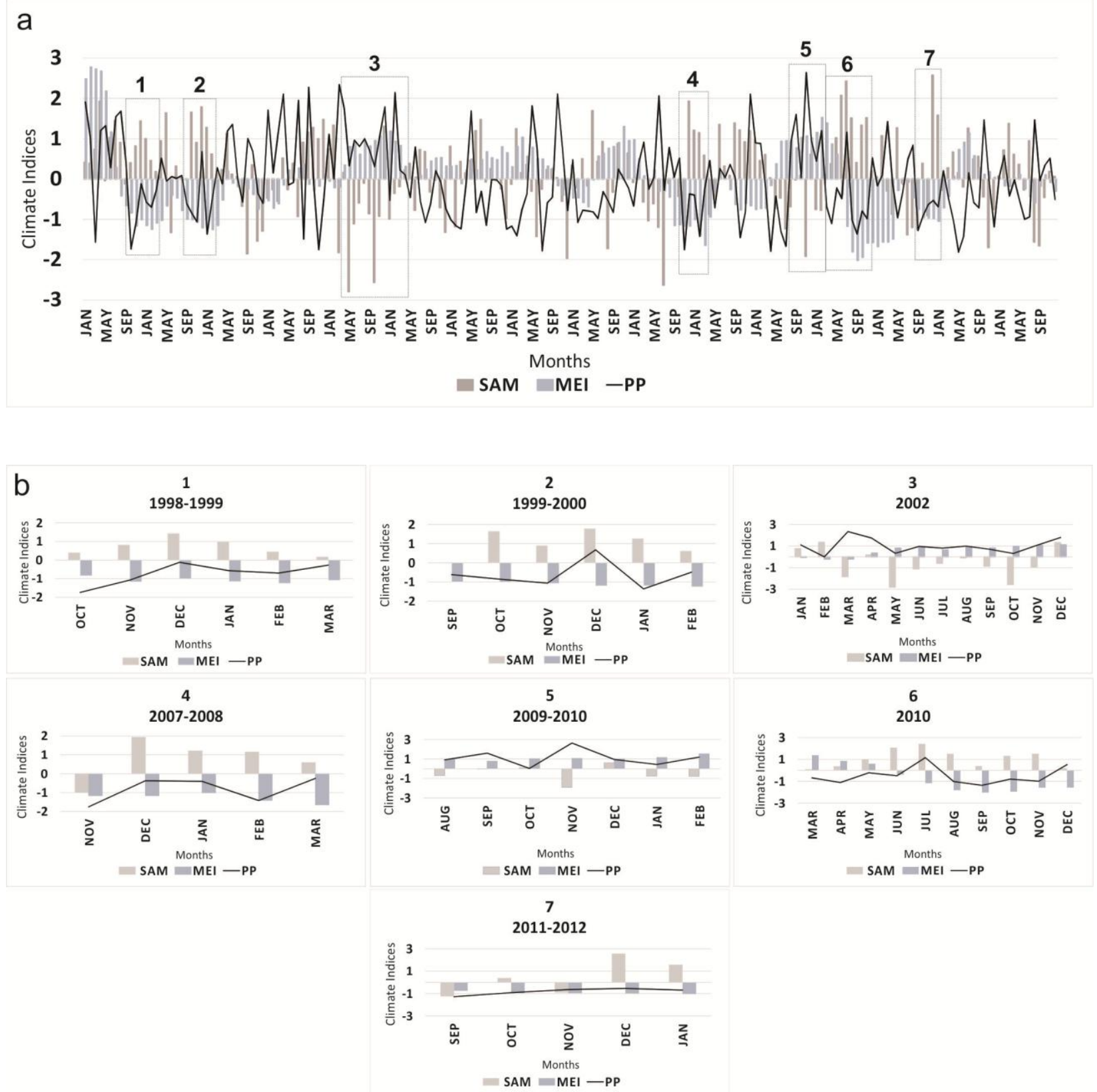

Figura 3 - Gráfico das anomalias mensais de precipitação (PP, linha preta) da Planície Costeira do Rio Grande do Sul, associadas aos respectivos índices SAM (coluna bege) e MEI (coluna cinza). Em a) a série completa 1998-2013, indicando os 7 eventos de anomalias de precipitação destacados em b) conforme a sequência da ocorrência. 
A rasa LP não possui tributários, dependendo exclusivamente da precipitação para manter seu nível de água (SCHOSSLER et al., 2017). Mesmo com o canal aberto, a maré de enchente não consegue introduzir água suficiente para o corpo lagunar, devido ao baixo prisma de maré (consequência do regime de micromarés da PCRGS). A baixa profundidade dessa depressão lagunar mantém os níveis de água muito baixos, com exceção da região do canal que pode atingir profundidades de até $3 \mathrm{~m}$. Baixos volumes de precipitação por longos períodos podem, inclusive, aumentar a salinidade da água restante (pequena intrusão de água marinha) desequilibrando todo ecossistema. Por outro lado, volumes de precipitação acima da média possibilitam a abertura natural do seu canal, fato de rara ocorrência.

Na tabela I estão descritas as características da precipitação nos eventos referentes as imagens escolhidas para exemplificar a variação hídrica na área da LP. No mês da imagem de PP- choveu apenas $87 \%$ da média de janeiro. Já no mês da imagem de PP+ choveu $72 \%$ acima da média de abril para a costa central.

Tabela I - Comparação entre os dados dos eventos de precipitação anômala negativa e positiva na área de estudo referentes as imagens do geoindicador

\begin{tabular}{c|c|c|c|c|c}
\hline $\begin{array}{c}\text { Condição } \\
\text { hídrica }\end{array}$ & $\begin{array}{c}\text { Data da } \\
\text { imagem }\end{array}$ & $\begin{array}{c}\mathrm{N}^{\mathrm{o}} \text { do } \\
\text { evento }\end{array}$ & $\begin{array}{c}\text { Média de } \\
\text { precipitação do } \\
\text { mês da imagem }\end{array}$ & $\begin{array}{c}\text { Total de } \\
\text { precipitação no } \\
\text { mês da imagem }\end{array}$ & $\begin{array}{c}\text { Índice de } \\
\text { anomalia }\end{array}$ \\
\hline $\mathrm{PP}-$ & $\begin{array}{c}25 \text { de março } \\
\text { de } 2008\end{array}$ & 6 & $108 \mathrm{~mm}$ & $95 \mathrm{~mm}$ & $-0,3$ \\
\hline $\mathrm{PP}+$ & $\begin{array}{c}02 \text { de abril } \\
\text { de } 2002\end{array}$ & 3 & $140 \mathrm{~mm}$ & $242 \mathrm{~mm}$ & $+1,6$ \\
\hline
\end{tabular}

A imagem selecionada para apresentar o período de estiagem é datada de março de 2008 (LN moderada) (4a). Se observamos primeiramente a tabela I, veremos que o índice de anomalia não é muito alto, porém, a estiagem já durava 6 meses. É possível perceber na figura 4a o fundo completamente exposto da LP, só possuindo água nos locais de maiores profundidades, como em seu canal. A porção sul da LP é a parte mais profunda do corpo lagunar (Arejano, 2006) e também ainda possuía água. É possível perceber também, comparando as imagens $4 \mathrm{a}$ e $4 \mathrm{~b}$, que o campo de dunas está seco na primeira imagem, enquanto na segunda imagem ele está úmido e os bancos e pontais da laguna estão parcialmente submersos. A imagem 4b, referente ao período de alta precipitação de 2002 (EN moderado e SAM-), é do mês de abril, quando o evento de PP+ recém havia iniciado. Porém, se somada precipitação total desses três primeiros meses, janeiro a março (a imagem é do início de abril) a precipitação ficou $58 \mathrm{~mm}$ acima da média do mesmo período. 


\begin{tabular}{|c|c|}
\hline $\begin{array}{l}\text { XVII Simpósio Brasileiro } \\
\text { de Geografia Fisica Aplicada }\end{array}$ & $\begin{array}{l}\text { OS DESAFIOS DA GEOGRAFIA FÍSICA NA FRONTEIRA DO CONHECIMENTO } \\
\text { Instituto de Geociências - Unicamp }\end{array}$ \\
\hline $\begin{array}{l}\text { I Congresso Nacional } \\
\text { de Geografia Física }\end{array}$ & $\begin{array}{c}\text { Campinas - SP } \\
28 \text { de Junho à } 02 \text { de Julho de } 2017\end{array}$ \\
\hline
\end{tabular}
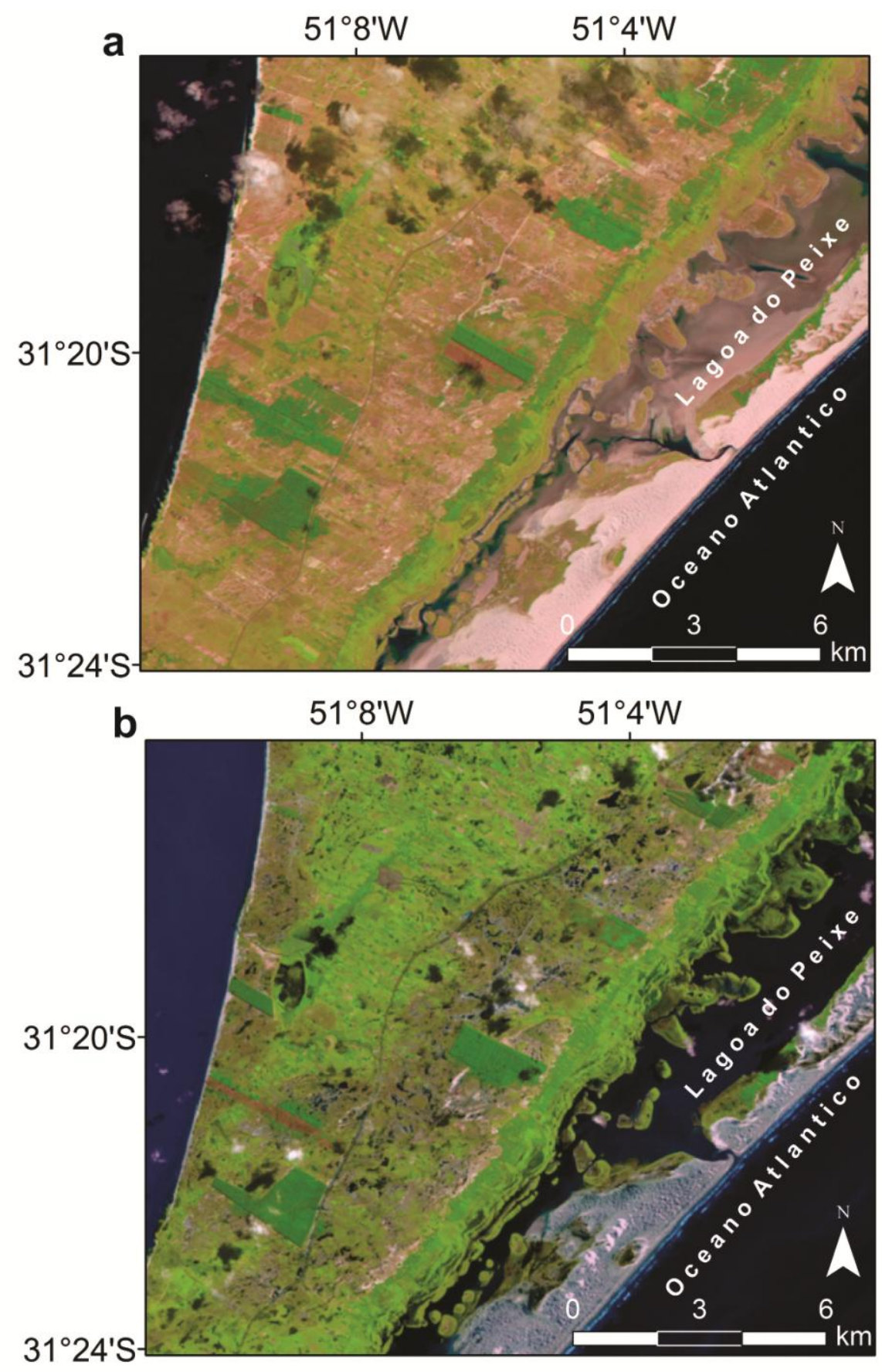

Figura 4 - Imagens Landsat TM escolhidas para exemplificar e comparar a área da Lagoa do Peixe em diferentes condições hídricas. Em a) imagem de PP-, referente ao evento 6, mostra o geoindicador completamente seco com seus pontais expostos, enquanto em b) a imagem de $\mathrm{PP}+$, referente ao evento 3 , apresenta o geoindicador e toda área bastante úmida, bem como os pontais parcialmente submersos.

Ainda, o ano anterior, 2001, vinha de meses de alta precipitação: $1842 \mathrm{~mm}$ de precipitação total, quando a média de precipitação total da costa central na série estudada é $1502 \mathrm{~mm}$. Quando a LP encontra-se cheia, 
e passa por períodos de alta precipitação, a barra de seu canal pode romper, o que é favorável em todos aspectos, pois a intrusão de água marinha transporta nutrientes, que favorecem toda fauna e flora pertencente ao ecossistema, bem como favorece o aumento da quantidade de peixes e crustáceos, fonte de renda da comunidade local.

\section{Discussões}

$\mathrm{Na}$ interpretação e descrição sobre os dados mensais contínuos foi possível identificar 7 eventos de anomalias positivas ou negativas de precipitação na série 1998-2013 na PCRGS. Geralmente esses eventos iniciam na primavera e se estendem até o final do verão. De acordo com Grimm et al. (1998, 2000) e Silvestri e Vera (2003), a primavera é a estação na qual a atmosfera apresenta maior variabilidade em suas características meteorológicas, sendo também a única estação que apresenta correlação significativa entre a precipitação anômala (ENOS e SAM), no sudeste da AS.

Gillet et al. (2006) destacam que entre as médias e altas latitudes com SAM+ (SAM-), os gradientes de pressão são acentuados (atenuados), mudando a direção dos ventos de oeste e intensificando (enfraquecendo) as velocidades sobre o oceano Austral. As anomalias de precipitação na PCRGS apresentam correlação negativa com o SAM, principalmente com o SAM+. Garreaud et al. (2009) afirmam que o SAM+ (SAM-) é dominante se a Temperatura da Superfície do Mar (TSM) e a convecção de umidade forem similares aos anos de LN (EN) ou quando há um aumento (redução) da variabilidade intrassazonal tropical, em escala mensal. De acordo com Silvestri e Vera (2003), quando ocorrem anticiclones (ciclones) anômalos de baixa frequência sobre o sudeste da AS, com SAM+ (SAM-), a atividade de ciclones é reduzida (incrementada), bem como a precipitação sobre essa região, reforçando a importância dos resultados aqui apresentados que confirmam o maior número de eventos de seca relacionados ao SAM+ na PCRGS. Para vários pesquisadores (e.g., THOMPSON E WALLACE, 2000; THOMPSON E SOLOMON, 2002; MARSHALL et al., 2004; GUPTA E ENGLAND, 2006) as mudanças climáticas têm aumentado a frequência de SAM+, o que amplifica os ventos de oeste sobre o Oceano Austral, reduzindo as velocidades dos ventos em regiões subtropicais. Esta tendência, provavelmente, está relacionada à carência do ozônio estratosférico (i.e., o "buraco" de ozônio) sobre a Antártica, e a influência do tempo meteorológico na baixa estratosfera (GARREAUD et al., 2009).

$\mathrm{Na}$ análise realizada entre a PP da área de estudo e o MEI foi obtida correlação positiva. Grimm et al. (2000) destacam que em eventos EN e LN a chuva não é homogênea no sul da AS, com exceção do sul do Brasil. Variabilidade na precipitação pode ser causada por diversos fatores e, no sul do Brasil, o ENOS 
pode aumentar (EN) ou reduzir (LN) a precipitação, devido ao incremento ou enfraquecimento do jato subtropical na primavera com formação de ciclones e anticiclones nesta região, sendo mais ocorrente eventos de PP- relacionados ao MEI- que os de PP+ associados ao MEI+ (GRIMM et al., 1998), concordando com os resultados aqui encontrados.

Haines (2008) classifica lagoas e lagunas costeiras de acordo com a morfodinâmica da embocadura de seus canais. O autor afirma que o nível d'água desses corpos d'água, bem como a abertura de seus canais, dependerá completamente da precipitação e da evaporação. A LP é um geoindicador das variações hídricas e ambientais na PCRGS, uma vez que sua baixa lamina d'água a torna ainda mais suscetível a anomalias de precipitação e todas consequências decorrentes (SCHOSSLER et al., 2017). Na imagem referente ao evento de PP-, do mês de março, a LP se encontra completamente seca. Períodos de estiagem, como os identificados na série temporal, podem intensificar a quantidade de areia transportada pelo vento, levando ao lento e completo assoreamento do corpo d'água, evolução geológica final da LP, descrita por Arejano (2006). A completa colmatação da LP deve ser devastadora para todo ecossistema, uma vez que as aves migratórias polares, que ali descansam, se alimentam e reproduzem, perderão esse ponto de repouso. Em abril de 2008, foi registrada uma das piores secas pelas quais o litoral médio do Rio Grande do Sul passou. Nesse ano, a média de precipitação foi de $1416 \mathrm{~mm}$ no PNLP, um pouco acima do esperado $(1258 \mathrm{~mm})$, com anomalia de valor positivo $(0,7)$ (SCHOSSLER et al, 2017). No entanto, os meses de março e abril juntos tiveram uma precipitação total de $160 \mathrm{~mm}$, valor pouco maior do que a média de março sozinho $(121 \mathrm{~mm})$. Essa anomalia negativa de março foi de quase um desvio padrão (somente $77 \mathrm{~mm}$ ), porém, mesmo dentro de sua média, abril de 2008 teve $92 \mathrm{~mm}$ de precipitação, o que não foi suficiente para recuperar a estiagem do mês de março. Março de 2008 obteve índice SAM+ $(1,29)$ com mais de um desvio padrão acima da média, bem como janeiro $(2,3)$ e fevereiro $(1,29)$, concordando com Gillet et al. (2009). O ano de 2007 teve índice médio do SAM de 2,08, podendo também ter modulado a precipitação do verão e início de outono em 2008. Já o sinal do ENOS, nos três primeiros meses de 2008 (janeiro, fevereiro e março), foram negativos, respectivamente -1,86, -1,89 e -1,15, valores que representam um período de LN (fase fria do ENOS), pois os sinais negativos do ENOS iniciaram no meio de 2007 e persistiram até meados de 2008, sempre com valores altos. De acordo com este estudo, o período interpretado nesse caso é típico, onde a precipitação ficou abaixo da média, simultaneamente ao SAM+ e ENOS-. Isso reforça as evidências que indicam que a associação de um período de ENOS- a um de SAM+, reduzem a precipitação no sudeste da AS, principalmente se forem meses contínuos. Desta forma, é possível afirmar que a forte anomalia negativa do ENOS e positiva do SAM, que se estenderam por meses entre 2007 e 2008, devem ter sido as responsáveis por tão intensa estiagem no PNLP. 


\section{Considerações Finais}

O estudo estatístico sobre a influência do SAM e do ENOS sobre a variabilidade da precipitação na PCRGS mostrou que tanto o SAM quanto o ENOS são correlacionados a anomalias de precipitação, principalmente a períodos de precipitação abaixo da média. Possivelmente, casos como o de 2008 na LP, citado na discussão desse artigo, seja um exemplo do que pode ocorrer quando o sinal intenso de LN surgir na primavera e se estender até o verão, simultaneamente a uma fase positiva do SAM. A região do PNLP é bastante sensível à estiagem, e o SAM+ e o ENOS- atuando juntos, podem, efetivamente, colocar esse ecossistema em risco, principalmente pelas variações de salinidades provocadas pela redução de entrada de água doce, que, consequentemente, irão afetar a variedades de espécies dentro do corpo lagunar. Outra possibilidade é a completa colmatação da LP.

Nas imagens da LP a variação hídrica é notável, principalmente quando observada as imagens de eventos de PP-. A PCRGS possui anomalias de precipitação correlacionadas ao SAM, e o maior número de eventos de PP- podem ser em decorrência do aumento de períodos correspondente ao $\mathrm{SAM}+$, fato atribuído as mudanças climáticas globais (THOMPSON E WALLACE 2000; THOMPSON E SOLOMON 2002; GUPTA E ENGLAND, 2006).

Todas essas respostas são potencialmente importantes na busca pela compreensão de como a intensificação dos modos de variabilidade climática no HS podem influenciar no comportamento da precipitação em regiões costeiras, e, por consequência, em ambientes frágeis a oscilações e mudanças climáticas. Além disso, ao analisar os índices ENOS e SAM, colocamos em evidência a influência mútua existente entre as massas atmosféricas das regiões subtropicais e polares no HS.

\section{Agradecimentos}

Os autores agradecem o Conselho Nacional de Desenvolvimento Científico e Tecnológico (CNPq) e Instituto Nacional de Ciência e Tecnologia da Criosfera (INCT da Criosfera) pelo apoio, suporte técnico e financeiro.

\section{Bibliografia}

AREJANO T.B. Geologia e evolução holocênica do sistema lagunar da "Lagoa do Peixe", litoral médio do Rio Grande do Sul, Brasil. 2006. 80f. Tese (Doutorado em Ciências), Porto Alegre, Programa de Pós-Graduação em Geociências, Instituto de Geociências, Universidade Federal do Rio Grande do Sul.

BAILY, B.; NOWELL, D. Techniques for monitoring coastal change: a review and case study. Ocean and Coastal Management, v.32, n.2, p. 85-95, 1996.

BERGER A.R. Assessing rapid environmental change using geoindicators. Environmental Geology, v. 32, p. 36-44, 1997. 
BJERKNES, J. Atmospheric teleconnections from the equatorial Pacific. Monthly Weather Review, v. 97, n.3, p. 163-172, 1969.

CALLIARI L.J. et al. Classificação Geomorfológica do Litoral do Rio Grande do Sul. In: Dieter Muehe. (Org.). Erosão e Progradação do Litoral Brasileiro. Brasília, DF: Ministério do Meio Ambiente, 1: p. 438-445, 2006.

CARRARO C.C. et al. Mapa Geológico do Estado do Rio Grande do Sul, escala 1: 1000 000. Porto Alegre, Instituto de Geociências,UFRGS, 1974.

GARREAUD R.D. et al. Present-day South American climate. Palaeogeography, Palaeoclimatolology, Palaeoecology, v. 281, n.3-4, p. 180-195, 2009.

GILLETT N.P. et al. Regional climate impacts of the Southern Annular Mode. Geophysical Research Letters, v.33, n.23, L23704, doi: 10.1029/2006GL027721, 4 p., 2006.

GONG D.; WANG, S. Definition of Antarctic Oscillation index. Geophysical Research Letters, v.26, n.4, p. 459-462, 1999.

GUPTA A.S.; ENGLAND, M.H. Coupled ocean-atmosphere-ice response to variations in the Southern Annular Mode. Journal of Climate, v.19, p. 4457-4486, 2006.

GRIMM A.M., et al. Climate variability in Southern South America associated with EI Niño and La Ninã events. Journal of Climate, v.13, p. 35-58, 2000.

GRIMM, A.M. et al. Precipitation anomalies in Southern Brazil associated with El Niño and La Niña Events. Journal of Climate, v.11, p. 2863-2880, 1998.

HAINES, P.E. ICOLL management - strategies for a sustainable future. BMT WBM Pty Ltd, Broadmeadow, NSW, 2008 .

HAIR J.F. et al. Análise Multivariada de Dados. Bookman, Porto Alegre, 687 p., 2009.

KJERFVE, B.;MAGILL, K.E. Geographic and hydrodynamic characteristics of shallow coastal lagoons. Marine Geology, v.88, p. 187-199, 1989.

MARSHALL, G.J. et al. Causes of exceptional atmospheric circulation changes in the southern hemisphere. Geophysical Research Letters, v.31, L14205, doi:10.1029/2004GL019952, 4 p., 2004

MORTON R.A. 2002. Coastal geoindicators of environmental change in the humid tropics. Environmental Geology, v.42, p. 711-724, 2002.

REBOITA M.S. et al. Relationship between Southern Annular Mode and Southern Hemisphere atmospheric systems. Revista Brasileira de Meteorologia, v.24, n. 1, p. 48-55, 2009.

SCHOSSLER, V. et al. Morphodynamics of the Lagoa do Peixe inlet, south coast of Brazil. Pesquisas em Geociências, v.44, n.1, p. 25-39, 2017.

SILVESTRI G.E.; VERA C.S. Antarctic Oscillation signal on precipitation anomalies over southeastern South America. Geophysical Research Letters, v.30, n.21, doi:10.1029/2003GL018277, 4 p., 2003.

THOMPSON D.W.J.; SOLOMON S. Interpretation of recent Southern Hemisphere climate change. Science, v.296, p. 895- 899, 2002.

THOMPSON, D.W.J; WALLACE J.M. 2000. Annular modes in the extratropical circulation. Part I: Month-tomonth variability. Journal of Climate,v.13, p. 1000-1016, 2000.

VILLWOCK J.A; TOMAZELLI L.J. Geologia Costeira do Rio Grande do Sul. Notas Técnicas do CECO-IGUFRGS, Porto Alegre, v.8, p. 1-45, 1995. 